OPEN ACCESS

Edited by:

Joshua D. Nosanchuk, Albert Einstein College of Medicine, United States

Reviewed by:

Radames J. B. Cordero,

Johns Hopkins University, United States

Andrew Alspaugh, Duke University, United States

*Correspondence: Oscar Zaragoza ozaragoza@isciii.es

Specialty section: This article was submitted to Fungi and Their Interactions, a section of the journal Frontiers in Microbiology

Received: 05 April 2017 Accepted: 13 July 2017

Published: 31 July 2017

Citation: Trevijano-Contador N, Rossi SA, Alves E, Landín-Ferreiroa $S$ and

Zaragoza O (2017) Capsule Enlargement in Cryptococcus neoformans Is Dependent on Mitochondrial Activity.

Front. Microbiol. 8:1423. doi: 10.3389/fmicb.2017.01423

\section{Capsule Enlargement in Cryptococcus neoformans Is Dependent on Mitochondrial Activity}

\author{
Nuria Trevijano-Contador, Suelen A. Rossi, Elisabete Alves, Santiago Landín-Ferreiroa \\ and Oscar Zaragoza*
}

Mycology Reference Laboratory, National Centre for Microbiology, Instituto de Salud Carlos III, Madrid, Spain

Cryptococcus neoformans is an environmental encapsulated yeast that behaves as an opportunistic pathogen in immunocompromised individuals. The capsule is the main virulence factor of this pathogen. This structure is highly dynamic, and it can change its size and structure according to the environmental conditions. During infection, C. neoformans significantly enlarges the size of the capsule by the addition of new polysaccharide. It is believed that capsule growth is an energy-cost process, but this aspect has never been addressed. In this work, we have evaluated the role of mitochondrial activity on capsule growth using specific inhibitors of the electron respiratory chain. We observed that capsule growth was impaired in the presence of inhibitors of the respiratory chain as salicylhydroxamic acid or antimycin A. Furthermore, capsule growth correlated with an increase of the mitochondrial membrane potential and higher production of reactive oxygen species. Our results confirm that capsule growth depends on mitochondrial activity, and open new insights to understand the regulation of this process.

Keywords: Cryptococcus neoformans, capsule enlargement, mitochondria, reactive oxygen species, mitochondrial membrane potential

\section{INTRODUCTION}

Cryptococcosis is a systemic infectious disease mainly caused by fungal species from the Cryptococcus genus. Its incidence increased in the twentieth century due to the emergence of HIV (Casadevall and Perfect, 1998). With the development of highly active antiretroviral therapy, the incidence has been controlled in developed countries, although the associated mortality remains high (Mirza et al., 2003; Friedman et al., 2005; Lortholary et al., 2006; Chottanapund et al., 2007; Dromer et al., 2007; Jongwutiwes et al., 2007). Cryptococcus neoformans is the species with the higher prevalence among $\mathrm{HIV}^{+}$patients. Inhalation of infectious particles initiates a pulmonary infection (Casadevall and Perfect, 1998; Giles et al., 2009; Velagapudi et al., 2009; Botts and Hull, 2010; Heitman et al., 2011). Although the infection is normally controlled by immunocompetent hosts, the yeasts can proliferate and disseminate to the brain in patients with altered immune response, especially $\mathrm{HIV}^{+}$and individuals who have suffered organ transplantation (Casadevall and Perfect, 1998; Singh et al., 2008). In these patients, it can cause meningoencephalitis, which has associated a high mortality if it is not diagnosed and treated effectively (Casadevall and Perfect, 1998). The impact of the disease is particularly significant in developing countries, where it has been estimated that it causes more than 650,000 deaths per year (Park et al., 2009). 
The main phenotypic feature of $C$. neoformans is a capsule that surrounds the cell body (Benham, 1935) which confers physical, biochemical, and immunological properties to this microorganism. For this reason, the capsule has been the object of a great number of studies that have established their role as an important virulence factor (Chang and KwonChung, 1994; Zaragoza et al., 2009; O’Meara and Alspaugh, 2012). The capsule of C. neoformans is composed of highly hydrophilic polysaccharide with a water content of $99 \%$ of its total weight (Maxson et al., 2007a). The capsule contains two main types of polysaccharides: glucuronoxylomannan and glucuronoxylomannogalactan, and a small proportion of mannoproteins (Evans and Mehl, 1951; Bhattacharjee et al., 1978, 1984; Cherniak et al., 1980, 1982; Murphy et al., 1988; Zaragoza et al., 2009). The capsular polysaccharides are released to the extracellular medium (exopolysaccharide) in vesicles, although this polysaccharide has different structure and antigenic properties than the one attached to the capsule (Rodrigues et al., 2007; Frases et al., 2008). The capsule and exopolysaccharides play an important role during infection because they have detrimental effects on the host (Vecchiarelli, 2000; McFadden and Casadevall, 2001; Zaragoza et al., 2009). Among others, the capsule inhibits the phagocytosis of the pathogen, blocks the migration and differentiation of lymphocytes, decreases antibodies production and induces apoptosis (Mitchell and Friedman, 1972; Murphy and Cozad, 1972; Lipovsky et al., 2000; Ellerbroek et al., 2002; Monari et al., 2008). These properties contribute to immune evasion. In addition, C. neoformans is an opportunistic intracellular pathogen, and the capsule has also an important role in the survival of the yeasts inside phagocytic cells (Steenbergen et al., 2001; Tucker and Casadevall, 2002; Johnston and May, 2013).

The size of the capsule is not constant, and during infection it increases significantly (Feldmesser et al., 2001). Capsule enlargement can be easily reproduced in vitro by incubation in low iron medium, enriched $\mathrm{CO}_{2}$ environment, mammalian serum, mannitol, or diluted nutrients at basic pH (Granger et al., 1985; Vartivarian et al., 1993; Zaragoza et al., 2003; Zaragoza and Casadevall, 2004; Guimaraes et al., 2010). Capsule growth occurs also in the presence of macrophage and amoeba extracts (Chrisman et al., 2010). In this sense, capsule growth confers resistance to stress conditions, such as reactive oxygen species (ROS) and antifungals so this process is presumably important to evade killing by phagocytic cells (Zaragoza et al., 2008).

Capsule enlargement requires the accumulation of a large amount of new polysaccharide that requires the action of different enzymes that link the different monosaccharides by glycosidic bonds to yield a polysaccharide of a higher molecular weight (Pierini and Doering, 2001; Zaragoza and Casadevall, 2006; Doering, 2009; Frases et al., 2009; O’Meara and Alspaugh, 2012). It has been estimated that the increase in cell weight due to the capsule growth is about $20 \%$ of the total weight of the cells, and this process occurs in a few hours (Maxson et al., 2007b). For this reason, it is believed that this process is energetically costly for the cell. This is an important aspect, because capsule growth normally occurs in conditions of nutrient limitation. However, the metabolic changes and the molecular mechanisms that regulate capsule growth are not fully characterized, although several signaling pathways (cAMP and Hog1) and transcription factors (such as Cir1, Nrg1, Ada2, and Gat201) are required for capsule enlargement (Alspaugh et al., 1997; Zaragoza et al., 2003; Cramer et al., 2006; Liu et al., 2008; Haynes et al., 2011). In eukaryotes, energy is obtained mainly from the production of ATP during mitochondrial respiration. In animals, the electron transfer during respiration occurs through the complexes of the inner mitochondrial membrane known as classical pathway. Higher plants, algae, and fungi possess different electron transfer pathways In addition to the electron transfer from NADH to complex I (rotenone sensitive), there are also other $\mathrm{NAD}(\mathrm{P}) \mathrm{H}$ oxidases (rotenone-insensitive) which do not contribute to proton efflux to the intermembrane space (Rasmusson and Møller, 1991; Kerscher, 2000). Fungi and plants can use electrons of the respiratory chain through the alternative oxidases (AOX) pathway (Vanlerberghe, 2013). Finally, in some Candida spp., such as Candida albicans and Candida parapsilosis, a parallel pathway that uses parallel cytochrome $c$ proteins has been described (see Milani et al., 2001; Alonso-Monge et al., 2009; Figure 1). Since capsule growth is a process that requires the synthesis and accumulation of new polysaccharide, we argued that it is energetically costly for the cell. For this reason, we decided to investigate the role of the mitochondria on capsule growth. We demonstrate that inhibition of mitochondrial activity by blocking different complexes impairs capsule enlargement, and that this process is associated with changes in mitochondrial potential. Our data suggest that under the stress conditions that lead to capsule growth (such as nutrient-limitation), part of cellular energy is invested in capsule enlargement, which highlights the importance of this structure for the survival in the yeast.

\section{MATERIALS AND METHODS}

\section{Strains, Media, and Growth Conditions}

All experiments were performed with C. neoformans var. grubii strain H99 (Perfect et al., 1980). The yeasts were routinely grown in liquid Sabouraud medium at $30^{\circ} \mathrm{C}$ with moderate shaking $(150 \mathrm{rpm})$. For capsule induction, the cells were transferred to capsule inducing media (10\% Sabouraud buffered at pH 7.3 with $50 \mathrm{mM}$ MOPS) for $0,3,6$, and $24 \mathrm{~h}$ (Zaragoza and Casadevall, 2004).

\section{Metabolic Inhibitors}

We have tested the following compound which inhibit specific complexes of electron transport chain: antimycin A (Sigma-Aldrich, stock $1.82 \mathrm{mM}$ in ethanol 96\%), oligomycin (Sigma-Aldrich, stock $1.26 \mathrm{mM}$, in ethanol), potassium cyanide (KCN, Sigma-Aldrich, stock $80 \mathrm{mM}$ in distilled water), salicylhydroxamic acid (SHAM, Sigma-Aldrich, stock $160 \mathrm{mM}$ in ethanol), rotenone (Sigma-Aldrich, stock $100 \mathrm{mM}$ in DMSO), and sodium azide (Sigma-Aldrich, stock $150 \mathrm{mM}$ in distilled water). Rotenone inhibits complex I of electron transport chain, antimycin A inhibits complex III, SHAM inhibits alternative 


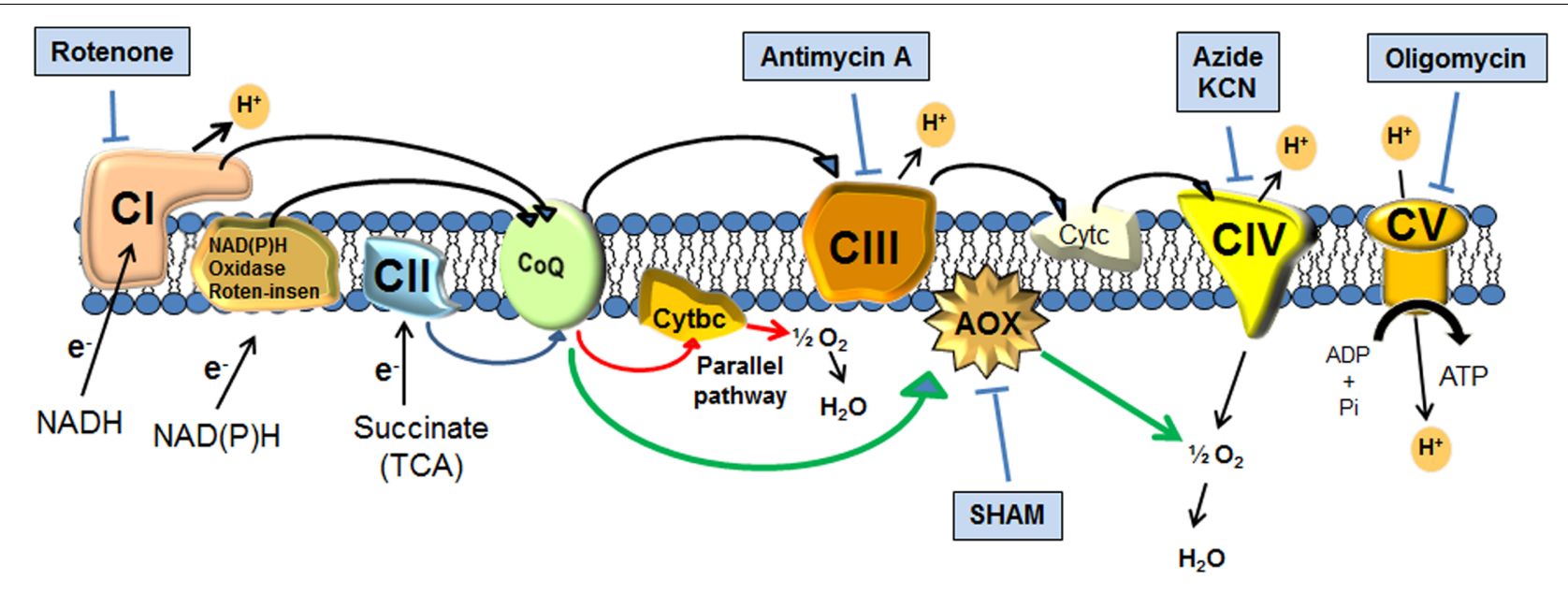

FIGURE 1 | Scheme of the mitochondrial respiratory chain (modified from Alonso-Monge et al., 2009) and of the different electron transfer pathways: classical, alternative rotenone-insensitive, parallel (red arrows) and alternative oxidases (green arrows). The scheme also represents the target of the main respiratory inhibitors.

cytochrome oxidative pathway, $\mathrm{KCN}$ and sodium azide the complex IV and Oligomycin inhibits complex V.

\section{Growth Curves in the Presence of Mitochondrial Inhibitors}

To perform growth curves, the cells were harvested with centrifugation at 3,000 $\mathrm{g}$ for $3 \mathrm{~min}$ and washed three times with phosphate-buffered saline (PBS). Cellular suspensions were prepared at $2 \times 10^{5}$ cells $/ \mathrm{mL}$ and inoculated in triplicate in a 96-well plate. Serial 1:2 dilutions of the inhibitor stocks were performed with PBS at the following concentrations: KCN from 20 to $2.5 \mathrm{mM}$, antimycin A from 3.6 to $0.22 \mu \mathrm{M}$, Oligomycin from 15 to $0.94 \mu \mathrm{M}$, SHAM from 4 to $0.47 \mathrm{mM}$, rotenone from 250 to $15.6 \mu \mathrm{M}$ and sodium azide from 7.6 to $0.003 \mathrm{mM}$. Seventy-five microliters of the inhibitors were mixed with the same volume of the yeast cells suspensions prepared in Sabouraud $2 \times$ in $96-$ well plates which was incubated at $30^{\circ} \mathrm{C}$ with moderate shaking in a spectrophotometer iEMS (Thermo Fisher Scientific). Optical density was measured at $540 \mathrm{~nm}$ every hour for $48 \mathrm{~h}$. Data were analyzed with GraphPad Prism 5.

We also tested if the inhibitors had fungistatic or fungicidal effect on C. neoformans. For this purpose, after the $48 \mathrm{~h}$ of incubation in the 96-well plates as described above, $10 \mu \mathrm{L}$ from the wells of microdilution plates were placed on Sabouraud agar plates. The growth of the yeast on the agar plates was evaluated after $48 \mathrm{~h}$ of incubation at $30^{\circ} \mathrm{C}$.

\section{Induction of Capsule Growth in the Presence of Mitochondrial Inhibitors}

Cells from H99 strain were incubated capsule induction medium or Sabouraud at $10^{6}$ cells $/ \mathrm{mL}$ in the presence of different mitochondrial inhibitors (from a $100 \times$ stock solution). Parallel samples with the same volume of the corresponding solvent were carried out as control. The flasks were incubated overnight at $37^{\circ} \mathrm{C}$. To observe and measure the size of the capsule, $10 \mu \mathrm{L}$ of a cell suspension were mixed with an India ink and observed in a Leica DMI 3000B microscope. To calculate capsule volume, the diameter of the whole cell and the cell body were each measured with Adobe Photoshop 7.0 and capsule volume was defined as the difference between the volume of the whole cell (yeast cell + capsule) and the volume of the cell body. Twenty cells were measured for each determination.

\section{Cellular Viability Measured by Flow Cytometry Assay}

Cells were treated with mitochondrial inhibitors during capsule induction as described above. Then, the cells were collected by centrifugation $(3,000 \mathrm{~g}, 3 \mathrm{~min})$, washed twice with PBS and adjusted to $10^{6}$ cells $/ \mathrm{mL}$. An untreated sample was used as negative control. In parallel, a sample was placed a $60^{\circ} \mathrm{C}$ during $30 \mathrm{~min}$ as a control of heat-killed cells. Propidium iodide (SigmaAldrich, St. Louis) was added at $5 \mu \mathrm{g} / \mathrm{mL}$ and fluorescence of the dead cells was measured using a FacsCalibur cytometer (BD Biosciences, Woburn, MA, United States) in the FL3 channel. Data obtained were analyzed with the programs CellQuest (BD Biosciences) and FlowJo (Tree Star Inc, Ashland, OR, United States).

\section{Real-Time PCR}

RNA extraction was performed using Trizol reagent (Ambion RNA by Life technologies) following the manufacturer's recommendations with minor modifications. The cells were disrupted with glass beads using a FastPrep-24 $\left(\mathrm{MP}^{\mathrm{TM}}\right)$ for $5 \mathrm{~min}$, alternating $20 \mathrm{~s}$ shaking with $1 \mathrm{~min}$ on ice. The RNAs were quantified using the Nanodrop 8000 Spectrophotometer (Thermo Fischer Scientific). RNA samples $(0.1 \mu \mathrm{g} / \mu \mathrm{L})$ were treated with DNase using the DNA-free ${ }^{\text {TM }}$ kit (Thermo Fisher Scientific). cDNAs were generated using the iScrip ${ }^{\mathrm{TM}}$ cDNA synthesis Kit (Bio-Rad) following the manufacturer's recommendations. The RTPCR was performed using SsoAdvanced ${ }^{\mathrm{TM}}$ Universal $\mathrm{SYBR}^{\mathrm{R}}$ Green Supermix (Bio-Rad) using the COX1 (cytochrome $c$ 
A

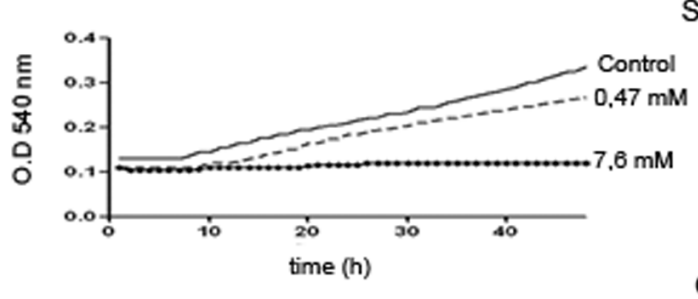

B

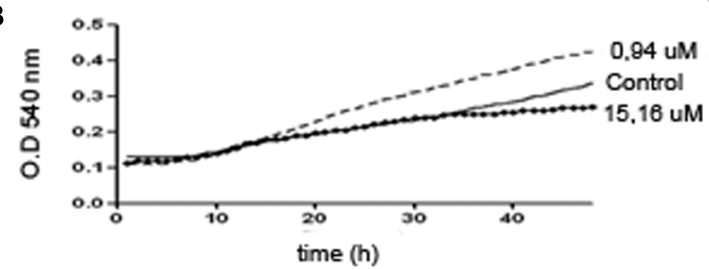

Sodium azide

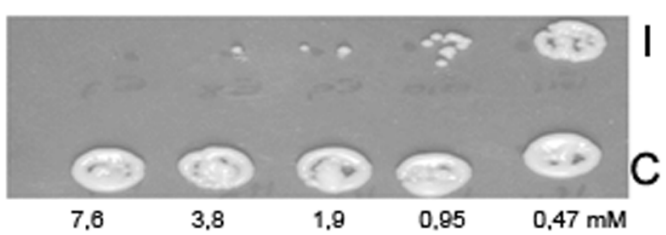

Oligomycin

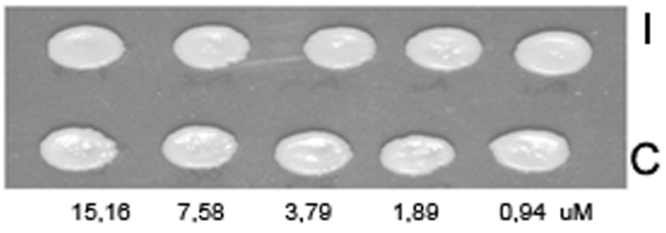

Antimycin A

C
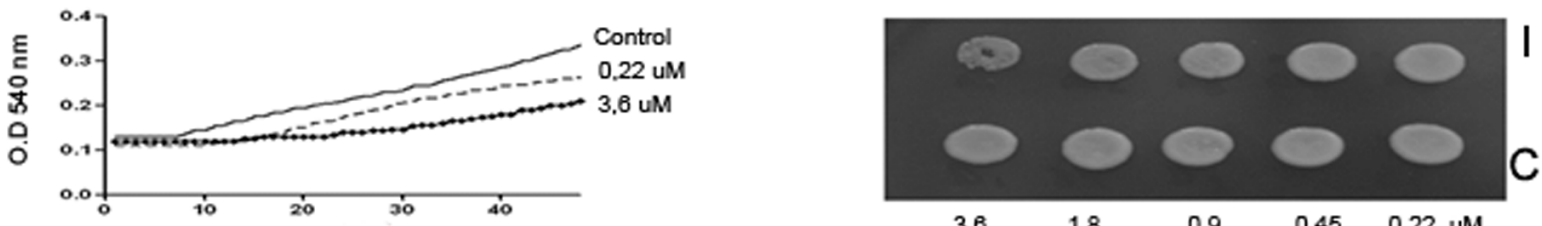

Potassium cyanide (KCN)
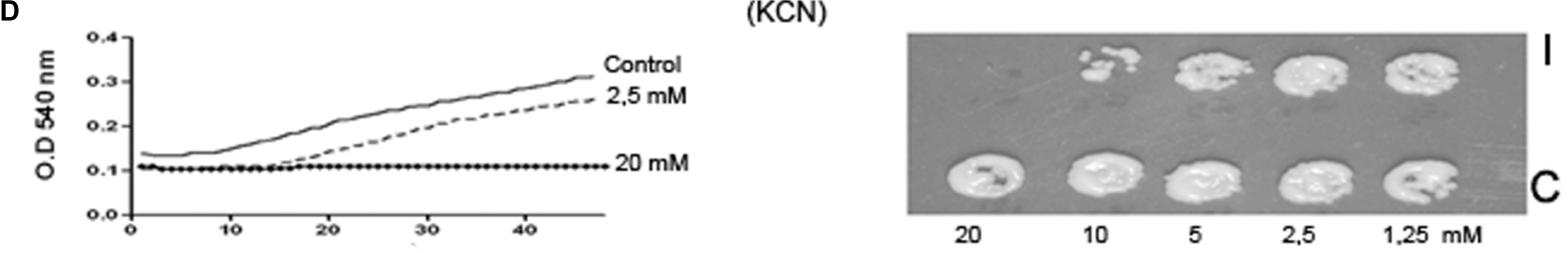

Salicylhydroxamic acid

E

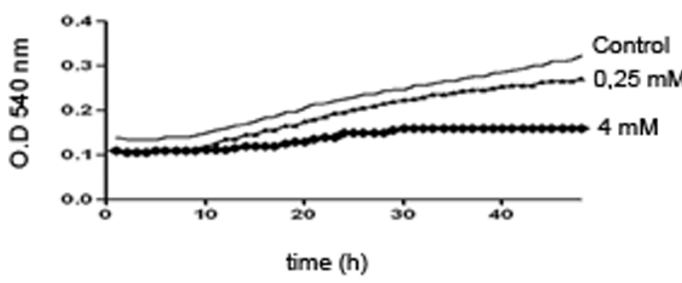

$\mathbf{F}$

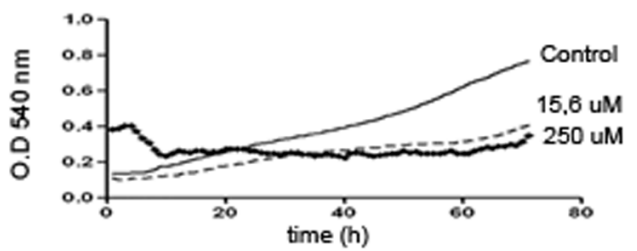

(SHAM)

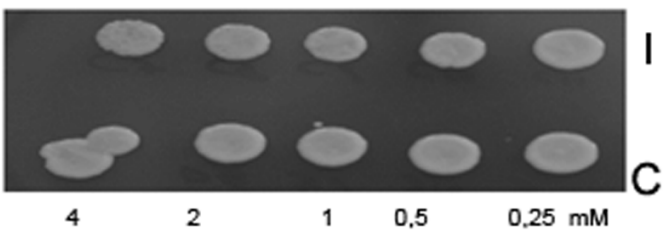

Rotenone

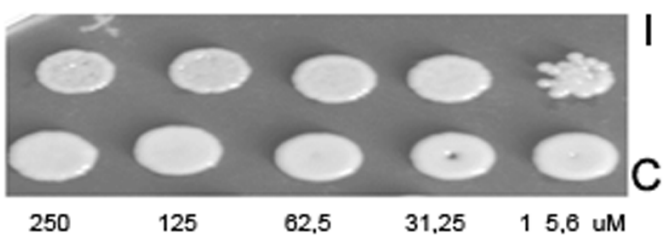

FIGURE 2 | Effect of mitochondrial inhibitors on Cryptococcus neoformans. C. neoformans cells were cultured in liquid Sabouraud in presence of different metabolic inhibitors [sodium azide (A), oligomycin (B), antimycin A (C), potassium cyanide (D), salicylhydroxamic acid (E), and rotenone (F)] in 96-well plates and growth curves were performed at 48 or $72 \mathrm{~h}$ at $30^{\circ} \mathrm{C}$. After this incubation time, $10 \mu \mathrm{L}$ from the wells incubated with the inhibitor (I) or control carrying only the same concentration of solvent (C) were placed on Sabouraud agar plates and incubated at $30^{\circ} \mathrm{C}$ during $48 \mathrm{~h}$. After that time, photographs were taken (right panels).

oxidase subunit I encoding gene) specific primers (COX1F CTGGTATGACACTACACAAGATGCCTC and COX1R ACCA 1GCTAGAACTGGGATACATAGGA) described in Alanio et al. (2011) in a total volume of $10 \mu \mathrm{L}$, in a Light Cycler $^{\mathrm{R}} 480$. As control, $18 \mathrm{~s}$ specific primers were used (18sF CCGTTGCT
AGAGGTGAAATTCTTAG and 18sR ATCTAATCGTTTTTGA TCCCCTAAC). The RT-PCR conditions were $\left(95^{\circ} \mathrm{C}\right.$ for $10 \mathrm{~min}$ and 40 cycles of amplification $\left(95^{\circ} \mathrm{C}\right.$ for $15 \mathrm{~s}, 58^{\circ} \mathrm{C}$ for $\left.1 \mathrm{~min}\right)$. Differences in gene expression were calculated using the $2^{\Delta \Delta \mathrm{Ct}}$ method (Pfaffl, 2004). 


\section{Mitochondrial Membrane Potential Assay}

Mitochondrial membrane potential was measured by flow cytometry using the dye Rhodamine 123 (Invitrogen), which are internalized and accumulated in the mitochondria by a process dependent on the mitochondrial membrane potential. Cells were harvested by centrifugation $(3 \mathrm{~min}$ at $3,000 \mathrm{~g}$ at room temperature), washed twice with PBS and suspended in the capsule inducing media at $10^{6}$ cells $/ \mathrm{mL}$. Ten milliliters from this suspension were incubated for 3,6 , and $24 \mathrm{~h}$ at $37^{\circ} \mathrm{C}$. The cells were suspended in sodium citrate buffer $(50 \mathrm{mM}, \mathrm{pH} 5)$, containing $2 \%$ glucose, and the rhodamine 123 was added at a final concentration of $35 \mu \mathrm{M}$. Cells were incubated at room temperature for $30 \mathrm{~min}$ and fluorescence was visualized by microscopy. Then, the fluorescence intensity was quantified using flow cytometry using a FacsCalibur (BD Biosciences, Woburn, MA, United States) and data were analyzed with CellQuest (BD Biosciences) and FlowJo (Tree Star Inc, Ashland, OR, United States).

\section{Detection of ROS with Fluorescent Probes}

The detection of ROS accumulation was performed with dihydrofluorescein diacetate (DHF, Sigma-Aldrich), which produces green fluorescence after attack by ROS. A suspension of $10^{6}$ cells $/ \mathrm{mL}$ was prepared and incubated at $37^{\circ} \mathrm{C}$ for different times in Sabouraud or in capsule-inducing medium. In addition, AmB $(1 \mu \mathrm{g} / \mathrm{mL})$ was added to same samples as a control of ROS production (Sangalli-Leite et al., 2011). After each incubation time DHF was added at a final concentration of $40 \mu \mathrm{M}$ and the samples were incubated a $37^{\circ} \mathrm{C}$ for $30 \mathrm{~min}$. Then, the cells were fixed with $p$-formaldehyde $4 \%$ during $30 \mathrm{~min}$ at room temperature and were washed with PBS. The fluorescence was quantified using a FacsCalibur cytometer (BD Biosciences, Woburn, MA, United States).

\section{Statistics}

The data was analyzed with GraphPad 5.0 software (GraphPad Software, La Jolla, CA, United States) and the KolmogorovSmirnov test was used to know the normality samples. ANOVA and $t$-test were used for normally distributed samples and Kruskal-Wallis and Mann-Whitney tests for samples considered not normal. Statistics difference was considered when $p<0.05$.

\section{RESULTS}

\section{Effect of Inhibition of the Respiratory Chain on Cell Growth}

To investigate to what extend capsule enlargement depends on the metabolic activity of the cell, we inhibited mitochondrial metabolism with different compounds and tested their effect on capsule production. First, we evaluated how these inhibitors affected the growth and viability of $C$. neoformans cells. We performed growth curves in Sabouraud liquid medium in presence of inhibitors for $48 \mathrm{~h}$ at $30^{\circ} \mathrm{C}$ to determine the minimal inhibitory concentration. All inhibitors caused a decrease in growth, which was dependent on the concentration (Figure 2, left part). The inhibition was observed from the lowest concentration used for each inhibitor, with the exception of oligomycin where all the concentrations evaluated grew equal or more than the control. In addition, no growth was observed at the highest concentrations of sodium azide and $\mathrm{KCN}$.

Then, we wanted to establish if the mitochondrial inhibitors had fungicidal or fungistatic effect on C. neoformans. For this purpose, we placed an aliquot of yeasts from the wells in which the inhibitors blocked growth from the 96-well plates in Sabouraud agar plates and incubated them for $24 \mathrm{~h}$ at $30^{\circ} \mathrm{C}$. We found that antimycin A, SHAM, and rotenone inhibited growth but did not kill the cells. In contrast, cyanide and sodium azide were fungicidal (Figure 2, right panels and Table 1).

\section{Effect of Specific Inhibitors of the Electron Respiratory Chain on Capsule Enlargement}

Next, we evaluated the role of mitochondrial activity on capsule growth. We chose those inhibitors that had fungistatic effect on C. neoformans. First, cells were grown in liquid Sabouraud at $30^{\circ} \mathrm{C}$ overnight and transferred to capsule inducing medium with the highest concentrations of the mitochondrial inhibitors. We found that these inhibitors impaired capsule enlargement compared with the control (Figures 3A,C,E). We also analyzed viability by flow cytometry during the capsule induction to discard that lack of capsule induction was due to cell death. So we measured the uptake of propidium iodide by the cells as an indicator of cell death. As show in Figures 3B,D,F, the cells did not become permeable to PI, indicating that none of the inhibitors produced cell death. Our results showed that inhibition of these mitochondrial complexes inhibits capsule enlargement.

\section{Changes in Mitochondrial Membrane Potential during Capsule Growth}

We examined if during capsule enlargement there were any changes in mitochondrial activity. Therefore, we evaluated the mitochondrial membrane potential as an indicator of the functionality of the mitochondria using the fluorescent probe Rhodamine 123 (Alonso-Monge et al., 2009), whose

TABLE 1 | Summary of the effect of different mitochondrial inhibitors on C. neoformans.

\begin{tabular}{lccc}
\hline Inhibitor & Solvent & $\begin{array}{c}\text { Inhibiting } \\
\text { concentration }\end{array}$ & $\begin{array}{c}\text { Antifungal } \\
\text { effect }\end{array}$ \\
\hline Antimycin A & Ethanol (96\%) & $0.22 \mu \mathrm{M}$ & Fungistatic \\
Oligomycin & $\mathrm{H}_{2} \mathrm{O}$ & - & No effect \\
Potassium cyanide & Ethanol (96\%) & $5 \mathrm{mM}$ & Fungicidal \\
Salicylhydroxamic acid & Ethanol (96\%) & $0.5 \mathrm{mM}$ & Fungistatic \\
Rotenone & $\mathrm{H}_{2} \mathrm{O}$ & $15.6 \mu \mathrm{M}$ & Fungistatic \\
Sodium azide & $\mathrm{DMSO}(100 \%)$ & $0.95 \mathrm{mM}$ & Fungicidal
\end{tabular}

The table represents the minimal inhibiting concentration and whether the inhibitors show fungicidal or fungistatic effect. 

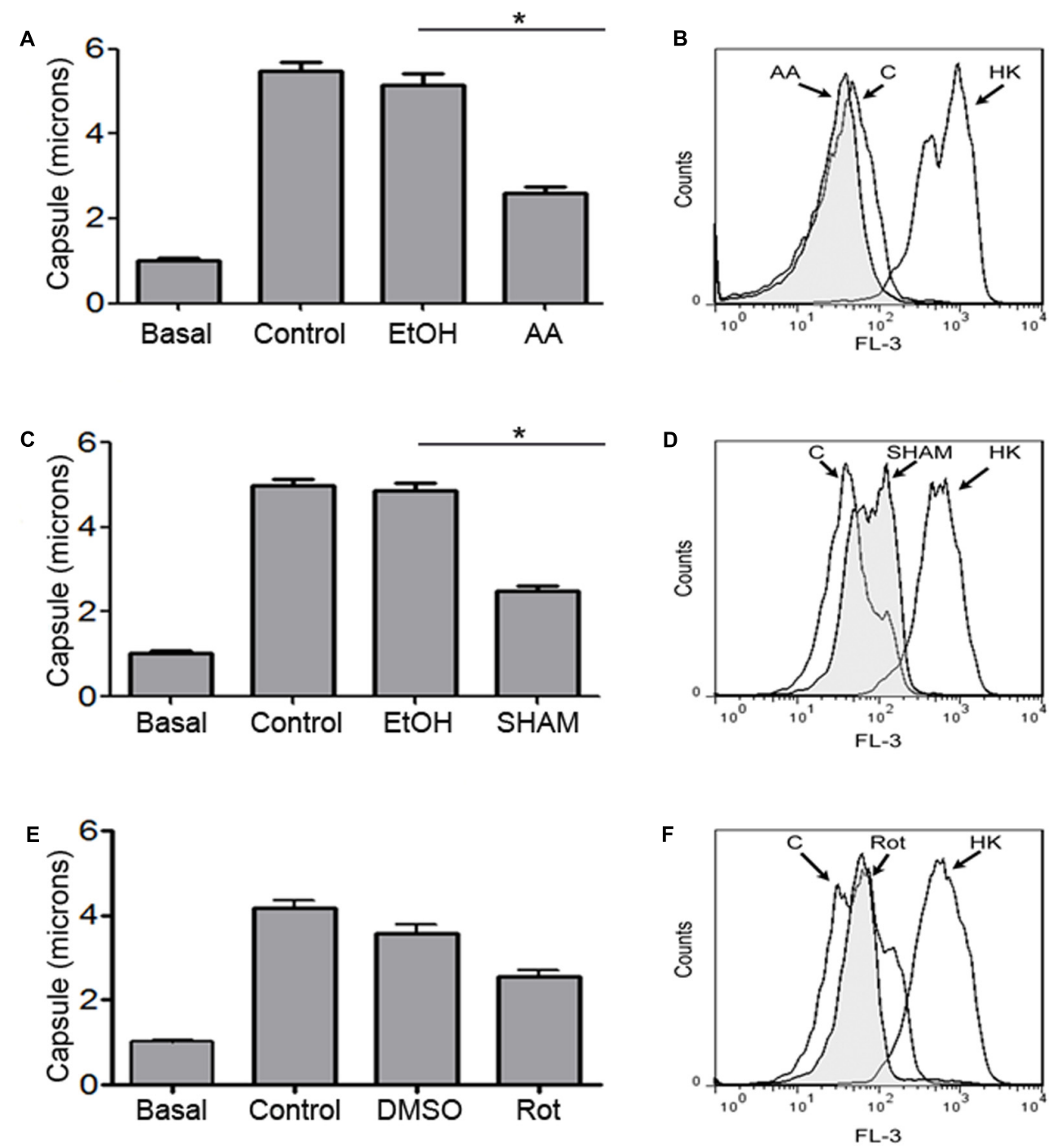

FIGURE 3 | Effect of mitochondrial inhibitors during capsule induction. Cells from $\mathrm{H} 99$ strain were grown in Sabouraud liquid medium at $30^{\circ} \mathrm{C}$ (basal) and then transferred to 10\% Sabouraud buffered at pH 7.3 with 50 mM MOPS in the presence of the highest concentration of antimycin A (3.6 $\mu$ M) (A,B), SHAM (4 mM) (C,D), and rotenone $(250 \mu \mathrm{M}) \mathbf{( E , F )}$ for $18 \mathrm{~h}$. In each case, control samples incubated only with the solvent (EtOH or DMSO) or without any solvent (Control) were carried out in parallel. After the incubation time, capsule size (A,C,E) was measured by suspending the cells in India ink as described in Section "Materials and Methods." Asterisks indicate significant differences $(p<0.05)$. In parallel, cellular viability was determined by measuring the uptake of propidium iodide by dead cells by flow cytometry (B,D,F). Heat-killed cells (HK) were included as positive controls. The experiment was performed in triplicate.

accumulation in the mitochondria depends of the membrane potential. We observed that cells accumulated more Rhodamine 123 when they were incubated in inducing medium compared to the same cells in Sabouraud (Figure 4). This result suggests that during capsule induction there was an increase in the mitochondrial membrane potential.

\section{Expression of COX1}

COX1 encodes cytochrome $c$ oxidase, which is a mitochondrial enzyme involved in respiration and thus energy production in C. neoformans. We evaluated the expression of the COX1 gene by real-time PCR during capsule induction or cells maintained in Sabouraud (Figure 5). We found that mRNA levels of
COX1 tended to be higher during incubation in capsule growth than in Sabouraud, being the difference more noticeable after $6 \mathrm{~h}$ of incubation. Interestingly, this effect was not due to an increase of the expression of the gene in our inducing conditions, but rather to a gradual decrease in the rich medium while COX1 expression remained constant in capsule growth conditions.

\section{Detection of ROS during Capsule Induction}

ROS are produced in the mitochondria as a result of the oxidative metabolism. We argued that if during capsule growth there are changes in mitochondrial activity, there might be also a 


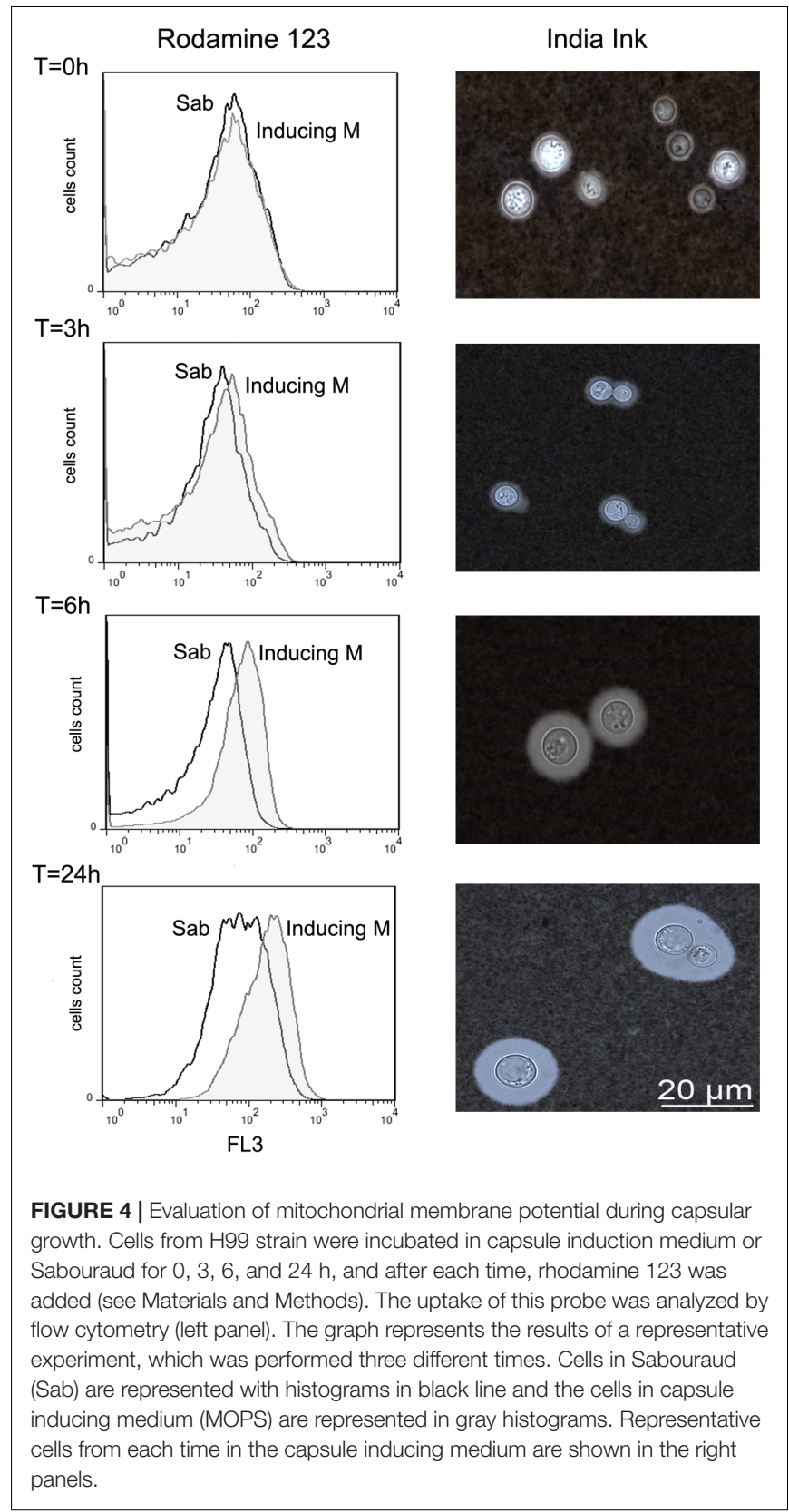

differential accumulation of ROS compared to capsule noninducing conditions. In this experiment, we observed that the ROS production increased during the induction medium over time. The ROS accumulation started after $3 \mathrm{~h}$ and was more evident after $24 \mathrm{~h}$ of incubation in comparison with the cells grown in Sabouraud medium (Figure 6). In all experiments, we included $\mathrm{AmB}(1 \mu \mathrm{g} / \mathrm{mL})$ as a positive control for (data not shown).

\section{DISCUSSION}

The polysaccharide capsule is the most characteristic feature of the fungal pathogen C. neoformans, and it is its main virulence

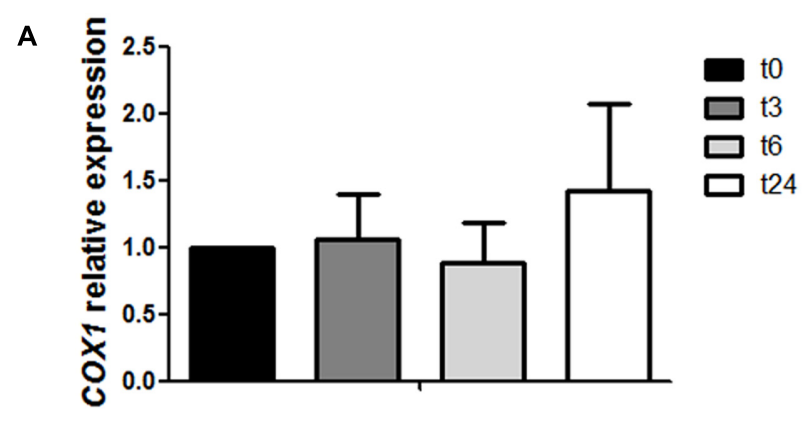

time (h)

B

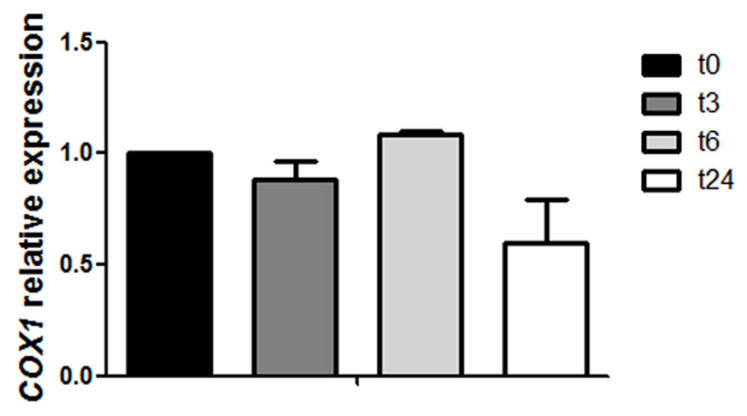

time (h)

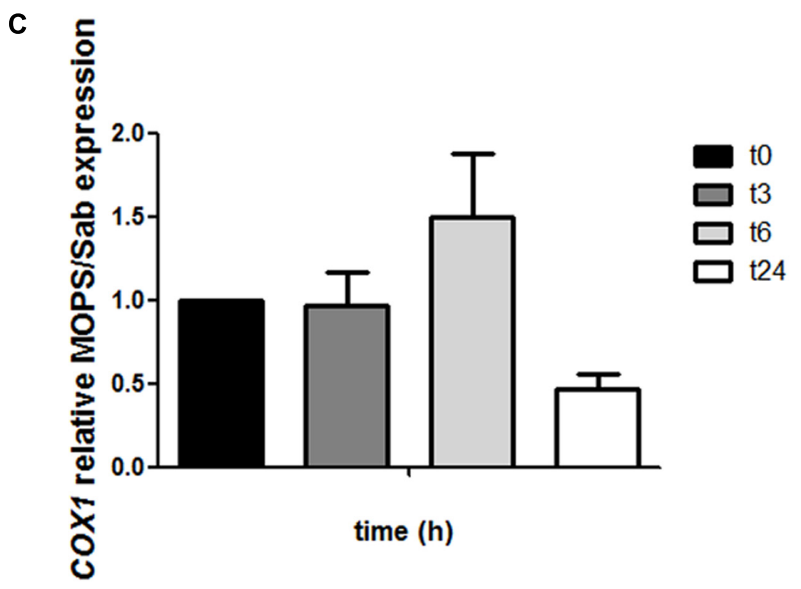

FIGURE 5 | Analysis of COX1 expression during capsule induction. Cells from $\mathrm{H} 99$ strain were grown in Sabouraud and capsule inducing medium at $37^{\circ} \mathrm{C}$ and RNA was isolated from samples were collected at different times $(0,3,6$, and $24 \mathrm{~h}$ ). cDNAs were obtained and relative expression of the COX1 gene was measured by real-time PCR as described in Section "Materials and Methods." COX1 gene expression at different time points in Sabouraud medium (A) and capsule inducing medium (B). Then, a relative fold change comparing at each time point the difference between the capsule inducing medium and Sabouraud was plotted in (C). This experiment was performed in triplicate.

factor (Zaragoza et al., 2009). For this reason, the synthesis and factors that regulate its size and structure have been largely studied (Pierini and Doering, 2001; McFadden et al., 2006; Zaragoza et al., 2006; Maxson et al., 2007b). However, some of the key aspects of the capsule still remain to be elucidated. For example, the molecular mechanisms that trigger capsule enlargement and cellular changes associated to this transition are 

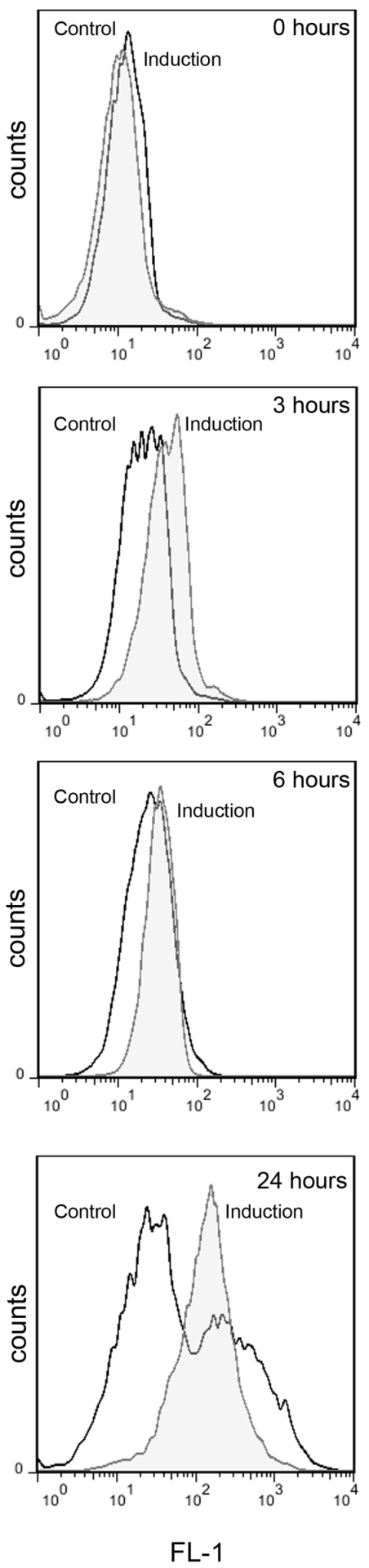

FIGURE 6 | Production of ROS during capsule induction. Cells from H99 strain were grown in Sabouraud overnight then transfer to the same medium (control, black line) or capsule induction medium (induction, gray filled histogram). The production of ROS was evaluated at time $0,3,6$, and $24 \mathrm{~h}$ by flow cytometry as described in Section "Materials and Methods." As positive control we used samples in the presence of AmB $(1 \mu \mathrm{g} / \mathrm{mL})$. The graph represents the results of a representative experiment, which was performed three different times. unknown. Capsule growth occurs by synthesis and addition of new polysaccharide (Zaragoza et al., 2006), and is dependent on protein synthesis (Doering, 2009). The increase in size elicited by $C$. neoformans pose a dramatic change for the cell. For example, it has been shown that during this process, the cell increases its dry mass around 20\% in a few hours (Maxson et al., 2007b), and the total volume of the capsule poses around $90 \%$ of the total volume of the cell. Most of the media that induce capsule growth are limited in the concentration of nutrients (i.e., serum, DME, and $\mathrm{CO}_{2}$ atmosphere, low iron medium). For this reason, we found intriguing that in these conditions there is such an accumulation of new polysaccharide on the capsule. Due to the magnitude of the change, we argued that capsule enlargement is a process that requires a high investment of the available energy in the cell. Since $C$. neoformans is a respiratory yeast, energy is mainly produced at the mitochondria. Therefore, we investigated to which extent capsule enlargement requires the correct functioning of the electron chain. Fungi present some differences in the electron transfer in the mitochondria compared to mammals. In particular, oxygen is reduced through several pathways. In addition to the classical respiratory chain through the mitochondrial complexes, electrons are transferred to oxygen through AOX and cytochrome $c$ (Kerscher, 2000; Alonso-Monge et al., 2009). We found that blocking the classical respiratory chain or the pathway of the AOX is enough to inhibit capsule growth. Our data indicates that mitochondria play an important role in capsule synthesis. Furthermore, the fact that inhibition of the AOX pathways with SHAM (which does not affect the classical respiratory chain) has a similar effect indicates that mitochondrial unbalance drastically affects cellular metabolism and capsule growth. At the moment, we do not know how alterations of AOX pathway exactly affect the mitochondrial respiratory chain (classical pathway) or how the cells exactly obtain the energy in these conditions. AOXs have been postulated to play a homeostatic role in the electron transfer in the mitochondria (Vanlerberghe, 2013), so it is possible that inhibition of this pathway there is an accumulation of ROS in the cells that cause deleterious effects effect in the cells. It is also possible that inhibition of AOX pathway results in a higher electron flux through the parallel pathway, which does not contribute ATP production, which could also limit the available energy of the cell and impair capsule enlargement. In our conditions, capsule growth occurs during nutrient starvation. In these conditions, we argue that the cells dedicate an important amount of energy in the adaptation responses that are required to survive in the new conditions. But our results suggest that capsule indicate that capsule growth can be considered a stress response which requires part of the energy produced by the cell. This is supported by the fact that capsule growth requires the synthesis of a significant amount of new polysaccharide.

We also confirmed that capsule enlargement correlates with mitochondrial changes, such as higher mRNA levels of COX1 and mitochondrial membrane potential. These data suggest that during this process, there is higher rate of electron transfer through the respiratory complex compared to basal conditions that results in a higher concentration of protons in the interperiplasmic space. The increase in mitochondrial 
activity also correlates with higher basal levels of ROS detected during capsule growth. The results from this work could should be complemented with other techniques that measure the respiration rate and oxygen consumption (with $\mathrm{O}_{2}$ detectors or Warburg respirometers). This work opens future research lines that will highlight the importance of specific metabolic pathways (such as the importance of the carbon and nitrogen source) on capsule growth. We also believe that future studies that determine the exact energy cost and energy flow during capsule growth are warranted.

We found that oligomycin did not have any effect on C. neoformans, which is in agreement with previous findings in the literature (Hua et al., 2000). This compound is an inhibitor or ATP synthase (complex V). At the moment, it is not known why this inhibitor is not active against $C$. neoformans, although it is possible that this yeast possesses a protein with some variants that makes the cells resistant.

Capsule growth is a key phenotype that determines the interaction of $C$. neoformans with the host and is a particular feature that is not expressed by other fungal pathogens. Several genes required for this process have been identified, such as ADA2 and GAT201 (Liu et al., 2008; Haynes et al., 2011). However, there are many aspects about this process that remain unknown. For example, capsule growth occurs in the G1 phase of cell cycle (Garcia-Rodas et al., 2014), but the link between the addition of polysaccharide to the capsule and cell cycle regulation has not been determined. Another intriguing aspect is the regulation of capsule size, and more in particular, why the size of the capsule does not increase more than a certain size (Zaragoza et al., 2006). In this work, we have addressed a novel aspect of capsule growth, which is the relationship with the cell metabolism. The availability of

\section{REFERENCES}

Alanio, A., Desnos-Ollivier, M., and Dromer, F. (2011). Dynamics of Cryptococcus neoformans-macrophage interactions reveal that fungal background influences outcome during cryptococcal meningoencephalitis in humans. mBio 2:e015811. doi: $10.1128 / \mathrm{mBio} .00158-11$

Alonso-Monge, R., Carvaihlo, S., Nombela, C., Rial, E., and Pla, J. (2009). The Hog1 MAP kinase controls respiratory metabolism in the fungal pathogen Candida albicans. Microbiology 155(Pt 2), 413-423. doi: 10.1099/mic.0. 023309-0

Alspaugh, J. A., Perfect, J. R., and Heitman, J. (1997). Cryptococcus neoformans mating and virulence are regulated by the G-protein alpha subunit GPA1 and cAMP. Genes Dev. 11, 3206-3217. doi: 10.1101/gad.11.23.3206

Benham, R. W. (1935). Cryptococci: their identification by morphology and by serology. J. Infect. Dis. 57, 255-274. doi: 10.1093/infdis/57.3.255

Bhattacharjee, A. K., Bennett, J. E., and Glaudemans, C. P. (1984). Capsular polysaccharides of Cryptococcus neoformans. Rev. Infect. Dis. 6, 619-624. doi: 10.1093/clinids/6.5.619

Bhattacharjee, A. K., Kwon-Chung, K. J., and Glaudemans, C. P. (1978). On the structure of the capsular polysaccharide from Cryptococcus neoformans serotype C. Immunochemistry 15, 673-679. doi: 10.1016/0161-5890(78) 90041-X

Botts, M. R., and Hull, C. M. (2010). Dueling in the lung: how Cryptococcus spores race the host for survival. Curr. Opin. Microbiol. 13, 437-442. doi: 10.1016/j. mib.2010.05.003

Casadevall, A., and Perfect, J. (1998). Cryptococcus neoformans. Washington, DC: ASM. energy and mitochondrial functioning is a key process in the cell to ensure the correct response of the cell to environmental stimuli and challenges, and many stress factors induce changes in mitochondrial metabolism and ROS accumulation. We hypothesize that capsule enlargement is an important process to protect against stress factors, and for this reason, a significant amount of the energy of the cell is invested in increasing capsule size.

Our results open new questions on the field, such as what the metabolic cost of capsule enlargement and how the cells rearrange their metabolism during these conditions.

\section{AUTHOR CONTRIBUTIONS}

NT-C, SR, EA, and SL-F participated in experimental design, development of the experiments, and preparation of the manuscript. OZ participated in experimental planning and writing of the manuscript.

\section{FUNDING}

OZ is funded by grant SAF2014-54336-R from the Spanish Ministry for Economics and Competitivity. NT-C is supported by a FPI fellowship (reference BES-2012-051837). SR is supported by a grant from Ciências sem fronteiras (202436/2015-2). EA had a grant from Erasmus+ program (Erasmus code PCOVILHA01). SL-F participated in this work in the frame of a Master in 'Parasitology and Microbiology: Research and Development' from the Pharmacy and Biology Faculties from the Complutense University of Madrid.

Chang, Y. C., and Kwon-Chung, K. J. (1994). Complementation of a capsuledeficient mutation of Cryptococcus neoformans restores its virulence. Mol. Cell. Biol. 14, 4912-4919. doi: 10.1128/MCB.14.7.4912

Cherniak, R., Reiss, E., Slodki, M. E., Plattner, R. D., and Blumer, S. O. (1980). Structure and antigenic activity of the capsular polysaccharide of Cryptococcus neoformans serotype A. Mol. Immunol. 17, 1025-1032. doi: 10.1016/01615890(80)90096-6

Cherniak, R., Reiss, E., and Turner, S. (1982). A galactoxylomannan antigen of Cryptococcus neoformans serotype A. Carbohydr. Res. 103, 239-250. doi: 10.1016/S0008-6215(00)80686-2

Chottanapund, S., Singhasivanon, P., Kaewkungwal, J., Chamroonswasdi, K., and Manosuthi, W. (2007). Survival time of HIV-infected patients with cryptococcal meningitis. J. Med. Assoc. Thai. 90, 2104-2111.

Chrisman, C. J., Alvarez, M., and Casadevall, A. (2010). Phagocytosis of Cryptococcus neoformans by, and nonlytic exocytosis from, Acanthamoeba castellanii. Appl. Environ. Microbiol. 76, 6056-6062. doi: 10.1128/AEM. 00812-10

Cramer, K. L., Gerrald, Q. D., Nichols, C. B., Price, M. S., and Alspaugh, J. A. (2006). Transcription factor Nrg1 mediates capsule formation, stress response, and pathogenesis in Cryptococcus neoformans. Eukaryot. Cell 5, 1147-1156. doi: 10.1128/EC.00145-06

Doering, T. L. (2009). How sweet it is! Cell wall biogenesis and polysaccharide capsule formation in Cryptococcus neoformans. Annu. Rev. Microbiol. 63, 223-247. doi: 10.1146/annurev.micro.62.081307.162753

Dromer, F., Mathoulin-Pelissier, S., Launay, O., and Lortholary, O. (2007). Determinants of disease presentation and outcome during cryptococcosis: the CryptoA/D study. PLoS Med. 4:e21. doi: 10.1371/journal.pmed.0040021 
Ellerbroek, P. M., Hoepelman, A. I., Wolbers, F., Zwaginga, J. J., and Coenjaerts, F. E. (2002). Cryptococcal glucuronoxylomannan inhibits adhesion of neutrophils to stimulated endothelium in vitro by affecting both neutrophils and endothelial cells. Infect. Immun. 70, 4762-4771. doi: 10.1128/IAI.70.9.47624771.2002

Evans, E. E., and Mehl, J. W. (1951). A qualitative analysis of capsular polysaccharides from Cryptococcus neoformans by filter paper chromatography. Science 114, 10-11. doi: 10.1126/science.114.2949.10

Feldmesser, M., Kress, Y., and Casadevall, A. (2001). Dynamic changes in the morphology of Cryptococcus neoformans during murine pulmonary infection. Microbiology 147(Pt 8), 2355-2365. doi: 10.1099/00221287-147-8-2355

Frases, S., Nimrichter, L., Viana, N. B., Nakouzi, A., and Casadevall, A. (2008). Cryptococcus neoformans capsular polysaccharide and exopolysaccharide fractions manifest physical, chemical, and antigenic differences. Eukaryot. Cell 7, 319-327. doi: 10.1128/EC.00378-07

Frases, S., Pontes, B., Nimrichter, L., Viana, N. B., Rodrigues, M. L., and Casadevall, A. (2009). Capsule of Cryptococcus neoformans grows by enlargement of polysaccharide molecules. Proc. Natl. Acad. Sci. U.S.A. 106, 1228-1233. doi: 10.1073/pnas.0808995106

Friedman, G. D., Jeffrey Fessel, W., Udaltsova, N. V., and Hurley, L. B. (2005). Cryptococcosis: the 1981-2000 epidemic. Mycoses 48, 122-125. doi: 10.1111/j. 1439-0507.2004.01082.x

Garcia-Rodas, R., Cordero, R. J., Trevijano-Contador, N., Janbon, G., Moyrand, F., Casadevall, A., et al. (2014). Capsule growth in Cryptococcus neoformans is coordinated with cell cycle progression. mBio 5:e00945-14. doi: 10.1128/mBio. 00945-14 e00945-14

Giles, S. S., Dagenais, T. R., Botts, M. R., Keller, N. P., and Hull, C. M. (2009). Elucidating the pathogenesis of spores from the human fungal pathogen Cryptococcus neoformans. Infect. Immun. 77, 3491-3500. doi: 10.1128/IAI. 00334-09

Granger, D. L., Perfect, J. R., and Durack, D. T. (1985). Virulence of Cryptococcus neoformans. Regulation of capsule synthesis by carbon dioxide. J. Clin. Invest. 76, 508-516. doi: 10.1172/JCI112000

Guimaraes, A. J., Frases, S., Cordero, R. J., Nimrichter, L., Casadevall, A., and Nosanchuk, J. D. (2010). Cryptococcus neoformans responds to mannitol by increasing capsule size in vitro and in vivo. Cell Microbiol. 12, 740-753. doi: $10.1111 / j .1462-5822.2010 .01430 . x$

Haynes, B. C., Skowyra, M. L., Spencer, S. J., Gish, S. R., Williams, M., Held, E. P., et al. (2011). Toward an integrated model of capsule regulation in Cryptococcus neoformans. PLoS Pathog. 7:e1002411. doi: 10.1371/journal.ppat.1002411

Heitman, J., Kozel, T. R., Kwon-Chung, K. J., Perferct, J. R., and Casadevall, A. (2011). Cryptococcus. From Human Pathogen to Model Yeast. Washington, DC: ASM Press.

Hua, J., Meyer, J. D., and Lodge, J. K. (2000). Development of positive selectable markers for the fungal pathogen Cryptococcus neoformans. Clin. Diagn. Lab. Immunol. 7, 125-128. doi: 10.1128/cdli.7.1.125-128.2000

Johnston, S. A., and May, R. C. (2013). Cryptococcus interactions with macrophages: evasion and manipulation of the phagosome by a fungal pathogen. Cell. Microbiol. 15, 403-411. doi: 10.1111/cmi.12067

Jongwutiwes, U., Kiertiburanakul, S., and Sungkanuparph, S. (2007). Impact of antiretroviral therapy on the relapse of cryptococcosis and survival of HIVinfected patients with cryptococcal infection. Curr. HIV Res. 5, 355-360. doi: $10.2174 / 157016207780636551$

Kerscher, S. J. (2000). Diversity and origin of alternative NADH:ubiquinone oxidoreductases. Biochim. Biophys. Acta 1459, 274-283. doi: 10.1016/S00052728(00)00162-6

Lipovsky, M. M., Tsenova, L., Coenjaerts, F. E., Kaplan, G., Cherniak, R., and Hoepelman, A. I. (2000). Cryptococcal glucuronoxylomannan delays translocation of leukocytes across the blood-brain barrier in an animal model of acute bacterial meningitis. J. Neuroimmunol. 111, 10-14. doi: 10.1016/S01655728(00)00354-4

Liu, O. W., Chun, C. D., Chow, E. D., Chen, C., Madhani, H. D., and Noble, S. M. (2008). Systematic genetic analysis of virulence in the human fungal pathogen Cryptococcus neoformans. Cell 135, 174-188. doi: 10.1016/j.cell.2008.07.046

Lortholary, O., Poizat, G., Zeller, V., Neuville, S., Boibieux, A., Alvarez, M., et al. (2006). Long-term outcome of AIDS-associated cryptococcosis in the era of combination antiretroviral therapy. AIDS 20, 2183-2191. doi: 10.1097/01.aids. 0000252060.80704 .68
Maxson, M. E., Cook, E., Casadevall, A., and Zaragoza, O. (2007a). The volume and hydration of the Cryptococcus neoformans polysaccharide capsule. Fungal Genet. Biol. 44, 180-186. doi: 10.1016/j.fgb.2006.07.010

Maxson, M. E., Dadachova, E., Casadevall, A., and Zaragoza, O. (2007b). Radial mass density, charge, and epitope distribution in the Cryptococcus neoformans capsule. Eukaryot. Cell 6, 95-109. doi: 10.1128/EC.00306-06

McFadden, D., Zaragoza, O., and Casadevall, A. (2006). The capsular dynamics of Cryptococcus neoformans. Trends Microbiol. 14, 497-505. doi: 10.1016/j.tim. 2006.09.003

McFadden, D. C., and Casadevall, A. (2001). Capsule and melanin synthesis in Cryptococcus neoformans. Med. Mycol. 39(Suppl. 1), 19-30. doi: 10.1080/mmy. 39.1.19.30

Milani, G., Jarmuszkiewicz, W., Sluse-Goffart, C. M., Schreiber, A. Z., Vercesi, A. E., and Sluse, F. E. (2001). Respiratory chain network in mitochondria of Candida parapsilosis: ADP/O appraisal of the multiple electron pathways. FEBS Lett. 508, 231-235. doi: 10.1016/S0014-5793(01)03060-5

Mirza, S. A., Phelan, M., Rimland, D., Graviss, E., Hamill, R., Brandt, M. E., et al. (2003). The changing epidemiology of cryptococcosis: an update from population-based active surveillance in 2 large metropolitan areas, 1992-2000. Clin. Infect. Dis. 36, 789-794. doi: 10.1086/368091

Mitchell, T. G., and Friedman, L. (1972). In vitro phagocytosis and intracellular fate of variously encapsulated strains of Cryptococcus neoformans. Infect. Immun. 5 , 491-498.

Monari, C., Paganelli, F., Bistoni, F., Kozel, T. R., and Vecchiarelli, A. (2008). Capsular polysaccharide induction of apoptosis by intrinsic and extrinsic mechanisms. Cell. Microbiol. 10, 2129-2137. doi: 10.1111/j.1462-5822.2008. 01196.x

Murphy, J. W., and Cozad, G. C. (1972). Immunological unresponsiveness induced by cryptococcal capsular polysaccharide assayed by the hemolytic plaque technique. Infect. Immun. 5, 896-901.

Murphy, J. W., Mosley, R. L., Cherniak, R., Reyes, G. H., Kozel, T. R., and Reiss, E. (1988). Serological, electrophoretic, and biological properties of Cryptococcus neoformans antigens. Infect. Immun. 56, 424-431.

O'Meara, T. R., and Alspaugh, J. A. (2012). The Cryptococcus neoformans capsule: a sword and a shield. Clin. Microbiol. Rev. 25, 387-408. doi: 10.1128/CMR. 00001-12

Park, B. J., Wannemuehler, K. A., Marston, B. J., Govender, N., Pappas, P. G., and Chiller, T. M. (2009). Estimation of the current global burden of cryptococcal meningitis among persons living with HIV/AIDS. AIDS 23, 525-530. doi: 10.1097/QAD.0b013e328322ffac

Perfect, J. R., Lang, S. D., and Durack, D. T. (1980). Chronic cryptococcal meningitis: a new experimental model in rabbits. Am. J. Pathol. 101, 177-194.

Pfaffl, M. W. (2004). "Quantification strategies in real-time PCR," in $A-Z$ of Quantitative PCR, ed. S. A. Bustin (La Jolla, CA: International University Line (IUL)).

Pierini, L. M., and Doering, T. L. (2001). Spatial and temporal sequence of capsule construction in Cryptococcus neoformans. Mol. Microbiol. 41, 105-115. doi: 10.1046/j.1365-2958.2001.02504.x

Rasmusson, A. G., and Møller, I. M. (1991). NAD(P)H dehydrogenases on the inner surface of the inner mitochondrial membrane studied using inside-out submitochondrial particles. Physiol. Plant. 83, 357-365. doi: 10.1111/j.13993054.1991.tb00106.x

Rodrigues, M. L., Nimrichter, L., Oliveira, D. L., Frases, S., Miranda, K., Zaragoza, O., et al. (2007). Vesicular polysaccharide export in Cryptococcus neoformans is a eukaryotic solution to the problem of fungal trans-cell wall transport. Eukaryot. Cell 6, 48-59. doi: 10.1128/EC. 00318-06

Sangalli-Leite, F., Scorzoni, L., Mesa-Arango, A. C., Casas, C., Herrero, E., Gianinni, M. J., et al. (2011). Amphotericin B mediates killing in Cryptococcus neoformans through the induction of a strong oxidative burst. Microbes Infect. 13, 457-467. doi: 10.1016/j.micinf.2011.01.015

Singh, N., Dromer, F., Perfect, J. R., and Lortholary, O. (2008). Cryptococcosis in solid organ transplant recipients: current state of the science. Clin. Infect. Dis. 47, 1321-1327. doi: 10.1086/592690

Steenbergen, J. N., Shuman, H. A., and Casadevall, A. (2001). Cryptococcus neoformans interactions with amoebae suggest an explanation for its virulence and intracellular pathogenic strategy in macrophages. Proc. Natl. Acad. Sci. U.S.A. $98,15245-15250$. doi: 10.1073/pnas.261418798 
Tucker, S. C., and Casadevall, A. (2002). Replication of Cryptococcus neoformans in macrophages is accompanied by phagosomal permeabilization and accumulation of vesicles containing polysaccharide in the cytoplasm. Proc. Natl. Acad. Sci. U.S.A. 99, 3165-3170. doi: 10.1073/pnas.052702799

Vanlerberghe, G. C. (2013). Alternative oxidase: a mitochondrial respiratory pathway to maintain metabolic and signaling homeostasis during abiotic and biotic stress in plants. Int. J. Mol. Sci. 14, 6805-6847. doi: 10.3390/ijms14046805

Vartivarian, S. E., Anaissie, E. J., Cowart, R. E., Sprigg, H. A., Tingler, M. J., and Jacobson, E. S. (1993). Regulation of cryptococcal capsular polysaccharide by iron. J. Infect. Dis. 167, 186-190. doi: 10.1093/infdis/167.1.186

Vecchiarelli, A. (2000). Immunoregulation by capsular components of Cryptococcus neoformans. Med. Mycol. 38, 407-417. doi: 10.1080/mmy. 38.6.407.417

Velagapudi, R., Hsueh, Y. P., Geunes-Boyer, S., Wright, J. R., and Heitman, J. (2009). Spores as infectious propagules of Cryptococcus neoformans. Infect. Immun. 77, 4345-4355. doi: 10.1128/IAI.00542-09

Zaragoza, O., and Casadevall, A. (2004). Experimental modulation of capsule size in Cryptococcus neoformans. Biol. Proced. Online 6, 10-15. doi: 10.1251/bpo68

Zaragoza, O., and Casadevall, A. (2006). Monoclonal antibodies can affect complement deposition on the capsule of the pathogenic fungus Cryptococcus neoformans by both classical pathway activation and steric hindrance. Cell. Microbiol. 8, 1862-1876. doi: 10.1111/j.1462-5822.2006. 00753.x

Zaragoza, O., Chrisman, C. J., Castelli, M. V., Frases, S., Cuenca-Estrella, M., Rodriguez-Tudela, J. L., et al. (2008). Capsule enlargement in Cryptococcus neoformans confers resistance to oxidative stress suggesting a mechanism for intracellular survival. Cell. Microbiol. 10, 2043-2057. doi: 10.1111/j.1462-5822. 2008.01186.x

Zaragoza, O., Fries, B. C., and Casadevall, A. (2003). Induction of capsule growth in Cryptococcus neoformans by mammalian serum and $\mathrm{CO}(2)$. Infect. Immun. 71, 6155-6164. doi: 10.1128/IAI.71.11.6155-6164.2003

Zaragoza, O., Rodrigues, M. L., De Jesus, M., Frases, S., Dadachova, E., and Casadevall, A. (2009). The capsule of the fungal pathogen Cryptococcus neoformans. Adv. Appl. Microbiol. 68, 133-216. doi: 10.1016/S0065-2164(09) 01204-0

Zaragoza, O., Telzak, A., Bryan, R. A., Dadachova, E., and Casadevall, A. (2006). The polysaccharide capsule of the pathogenic fungus Cryptococcus neoformans enlarges by distal growth and is rearranged during budding. Mol. Microbiol. 59, 67-83. doi: 10.1111/j.1365-2958.2005. 04928.x

Conflict of Interest Statement: The authors declare that the research was conducted in the absence of any commercial or financial relationships that could be construed as a potential conflict of interest.

Copyright $\odot 2017$ Trevijano-Contador, Rossi, Alves, Landin-Ferreiroa and Zaragoza. This is an open-access article distributed under the terms of the Creative Commons Attribution License (CC BY). The use, distribution or reproduction in other forums is permitted, provided the original author(s) or licensor are credited and that the original publication in this journal is cited, in accordance with accepted academic practice. No use, distribution or reproduction is permitted which does not comply with these terms. 